\title{
Treatment of malignant pleural effusion
}

\author{
Ricardo Mingarini Terra ${ }^{1}$, Alberto Jorge Monteiro Dela Vega ${ }^{2}$ \\ ${ }^{1}$ Thoracic Surgery Division, Hospital das Clinicas HCFMUSP, Faculdade de Medicina, Universidade de Sao Paulo, São Paulo, SP, Brazil; ${ }^{2}$ Thoracic \\ Surgery Division, Instituto do Câncer do Estado de São Paulo, Universidade de Sao Paulo, São Paulo, SP, Brazil \\ Contributions: (I) Conception and design: RM Terra; (II) Administrative support: RM Terra; (III) Provision of study materials or patients: RM Terra; \\ (IV) Collection and assembly of data: RM Terra; (V) Data analysis and interpretation: All authors; (VI) Manuscript writing: All authors; (VII) Final \\ approval of manuscript: All authors. \\ Correspondence to: Ricardo Mingarini Terra, MD, PhD. Thoracic Surgery Division, Hospital das Clinicas HCFMUSP, Faculdade de Medicina, \\ Universidade de Sao Paulo, São Paulo, SP, Brazil. Email: rmterra@uol.com.br.
}

\begin{abstract}
Malignant pleural effusion (MPE) is a very disabling condition that often affects patients with advanced neoplasm. Conservative approach, repeated thoracentesis, pleurodesis and use of indwelling pleural catheters (IPC) are the main methods to deal with this condition. The ideal treatment must focus on symptom relief and has to take into account patient underlying diseases, performance status and necessity of adequate tissue sample for diagnosis. In a video we show techniques to perform video assisted thoracic surgery (VATS) pleural biopsy and talc poudrage pleurodesis.
\end{abstract}

Keywords: Pleura; pleurodesis; video-assisted thoracic surgery (VATS); malignant pleural effusion (MPE); thoracentesis

Received: 05 April 2018; Accepted: 26 April 2018; Published: 22 May 2018.

doi: 10.21037 /jovs.2018.05.02

View this article at: http://dx.doi.org/10.21037/jovs.2018.05.02

\section{Introduction}

Malignant pleural effusion (MPE) is defined as the presence of malignant cells in the pleural fluid. It is a common complication of metastatic cancer, affecting more than 150,000 patients in the US and it was responsible for 126,825 hospital admissions in $2012(1,2)$. MPE Is a very disabling condition, with a huge impact in quality of life (QoL) $(3,4)$. The majority of patients is symptomatic although about $25 \%$ can be asymptomatic. Dyspnea is the most common symptom but patients may present with cough, chest pain or other constitutional symptoms that can be also attributed to the primary tumor such as weight loss, anorexia and malaise (5). Lung and breast are the most frequent primary sites that originate pleural metastasis, followed by lymphomas and gastrointestinal tract tumors (1).

The treatment of MPE aims at preventing recurrence, improving symptoms and enhance QoL with minimal hospitalization. Different procedures can be used to adequately manage MPE. Some of them can be used together or sequentially (e.g., thoracocentesis and pleurodesis) and the choice of the best approach for each case must be determined taking into account clinical background, underlying diseases, performance status, family and medical support as well as adequate access medical services and devices.

\section{Treatment options}

\section{Conservative approach}

It is possible to choose not to intervene in the MPE if patient is asymptomatic, the volume of pleural effusion is small and if the pleural infusion is not likely to be caused by other diseases not requiring investigation. Individuals under chemotherapy may experience good control of the pleural effusion, especially in cases of lymphoma, small cell carcinoma and breast cancer (6). All pleural interventional procedures carry risks to patients so it is important to offer conservative approach when possible.

\section{Thoracentesis}

Thoracentesis consists in drainage of pleural cavity using small catheters (14-18 G). Although the effect of the procedure may be temporary due to the high chance of 
recurrence, thoracentesis can be the best option in very frail patients (ECOG 3-4), with poor life-expectancy or in those not fit for pleurodesis or for the use of an indwelling pleural catheter (IPC) $(5,6)$. Its advantages include its technical simplicity, the capacity of adequate drainage of the pleural space, and the possibility of being performed in an outpatient setting. There is not a rule for the maximum volume of fluid that can be drained in each procedure, but volumes over $1.5 \mathrm{~L}$ must be aspirated more carefully. Feller-Kopman et al. studied 185 patients that underwent thoracentesis and found that re-expansion pulmonary edema is a rare adverse effect $(0.5 \%)$ and that it was not related to the volume of fluid drained (7). Therefore there is not a sole parameter to determine the end of pleural drainage. In our department, we use gravitational drainage and try to drain the maximum amount of fluid; nonetheless, we use symptoms (cough, pain and Dyspnea) as a guidance to determine the right moment to stop the fluid drainage.

\section{Pleurodesis}

Pleurodesis is an efficient method to treat recurrent MPE. Many different agents such as silver nitrate, bleomycin, tetracycline, mitozantrone, mepacrine, corynebacterium parvum, iodopovidone have been studied over the years; and despite difficulties to prospectively compare all those agents, talc is regarded as the most effective and used agent for pleurodesis (8-13). The complete expansion of the lung is not a requisite for pleurodesis. Patients with partial apposition of the parietal and visceral pleural membranes can still benefit from pleurodesis $(5,14-17)$. In contrast, patients with complete trapped lung may not take advantage of pleurodesis and the use of IPC has shown to be a better option than thoracentesis.

\section{Talc slurry pleurodesis}

Talc slurry is the instillation of talc through a chest tube performed after radiologic confirmation of lung expansion which is usually 24-36 hours after the placement of the chest tube. It can be performed using a small-bore tube (12$14 \mathrm{~F}$ ) or large bore tubes (20-32 F). The size of the chest drain doesn't seem to influence the efficacy of pleurodesis, but the smaller tubes have been reported as less painful (18). Lidocaine is the most frequently used anesthetic and should be administered just before the pleurodesis at a maximum dose of $3 \mathrm{mg} / \mathrm{kg}$ (5). Usually, 3-6 g of sterile talc is diluted in a $100 \mathrm{~mL}$ saline solution. The tube is subsequently clamped for 1-2 hours $(5,19)$. The removal of the chest tube must be based on fluid volume and the time of removal does not seems to influence the result of pleurodesis. Some individuals submitted to talc slurry using small-bore tubes can be safely managed without hospitalization using day care units and close outpatient follow-up (20).

\section{Video assisted thoracic surgery (VATS) talc poudrage}

Intrapleural talc delivery can also be made by using talc poudrage that consists in the instillation of talc under video assisted thoracic surgery. Patients frequently undergo general anesthesia, but it can also be performed under sedation. An atomizer is used to spread 3-6 $\mathrm{g}$ of talc in the pleural cavity.

One of the greatest advantages of VATS talc poudrage is the capacity to provide adequate diagnosis. Due to the invasive nature of the procedure, patients with low performance status or important comorbidity are not good candidates for the operation.

\section{Talc slurry versus VATS talc poudrage}

There is still a great controversy in literature regarding which is the most effective technique for pleurodesis. Dresler et al. in a large (501 patients) randomized controlled trial (RCT) found no difference between the two methods when comparing successful pleurodesis after 30 days, even though the subgroup of patients with lung and breast cancer had better results with VATS talc poudrage (19). Clive et al. (21), in a meta-analysis, found better results for talc poudrage. Xia et al. in another meta- analysis also found better results for talc poudrage (22). Therefore, based on literature evidence, both techniques can be applied with similar results in terms of safety and effectiveness. As mentioned before, it is necessary to carefully consider patient background, performance status, and the necessity for pleural biopsy before choosing the more adequate technique.

\section{IPC}

IPC are semi-implantable devices that enable patients to drain pleural effusions at home using vacuum bottles, either by themselves or with family or caregiver support. Hospitalization in a regular ward or in a day-hospital facility is necessary for its placement, though. The catheter is inserted with ultrasound guidance and Seldinger technique 


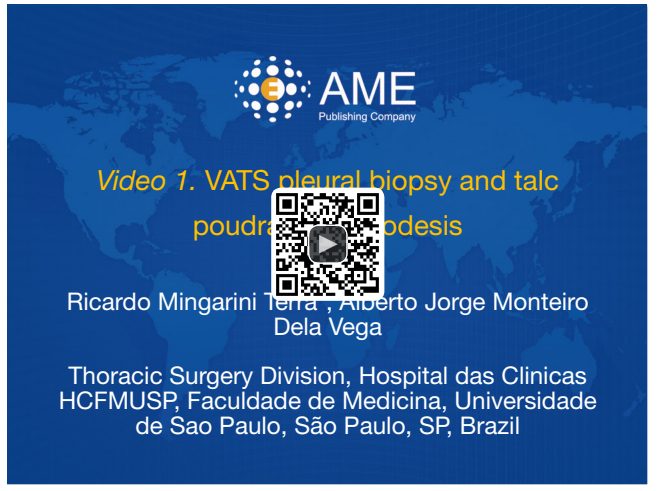

Figure 1 VATS pleural biopsy and talc poudrage pleurodesis (25). Available online: http://www.asvide.com/article/view/24892

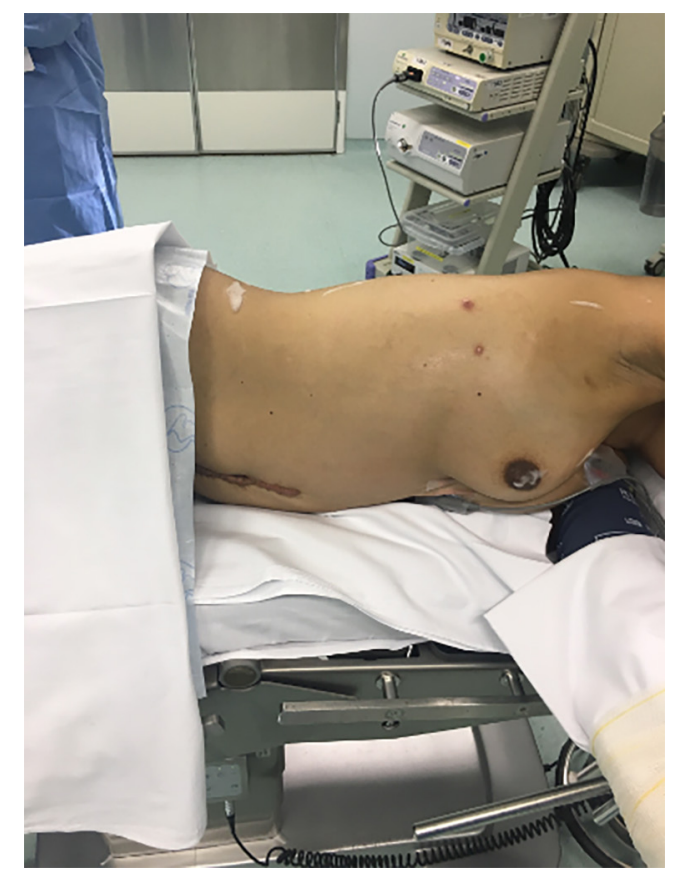

Figure 2 Position in the operation room.

and tunneling.

IPC has shown effectiveness in controlling symptoms of MPE by increasing QoL $(3,5,23)$ scores in several studies. Some studies have been published comparing IPC with pleurodesis and similar efficiency for the two approaches has been found. Thomas et al. in an RCT compared the two techniques in terms of hospitalization days and found a slight difference in favor of IPC $(10 \times 12$ days, $\mathrm{P}=0.3)$. Davies and colleagues (24) in a large randomized trial, compared
IPC with talc slurry pleurodesis in terms of improvement of dyspnea and found no significant difference. Overall, the use of IPC is an important tool to be used in patients with trapped lung that need recurrent thoracocentesis and can be considered as a good alternative to pleurodesis.

\section{VATS pleural biopsy and talc poudrage pleurodesis (Figure 1)}

\section{Patient selection and workup}

Patients with recurrent pleural effusion presenting with high concentration of protein and lymphocyte predominance and with history of advanced malignant disease are suspected to have MPE. In such condition, one of the options is to perform VATS biopsy in order to investigate the cause of pleural effusion and provide adequate pleurodesis at the same time. Patients with already diagnosed MPEs can be submitted to drainage and pleurodesis by talc slurry or by VATS and talc poudrage. Pleurodesis causes an important inflammatory reaction, because of that we normally do not perform pleurodesis in patients with low performance status (Karnofsky Performance Status <50)

\section{Pre-operative preparation}

* Patient are submitted to general anesthesia and oral intubation;

* Selective intubation is optional;

* Normally it is not necessary to use peridural anesthesia;

* The position is lateral decubitus with arms positioned in an elevated support (Figure 2).

\section{Equipment preference card}

* Video equipment with camera, light source, based on surgeon's preference;

* $30^{\circ} 10$ mm laparoscope;

* Atomizer for talc poudrage and an oxygen outlet to connect the atomizer;

* $5 \mathrm{~g}$ of sterile talc;

* $10.5 \mathrm{~mm}$ thoracic port.

\section{Procedure}

\section{Ports and incisions}

* Anterior incision in the $4^{\text {th }}$ or $5^{\text {th }}$ intercostal space (ICS) is made as the initial approach to the pleural cavity; 
* Caudal incision for $10 \mathrm{~mm}$ camera port, normally in $9^{\text {th }}$ or $10^{\text {th }}$ (ICS) in midaxillary line under direct view;

- Posterior port is optional. Normally placed in $8^{\text {th }}$ ICS posterior axillary line;

- Normally two ports are sufficient to adequate biopsy and pleurodesis.

\section{Pleural cavity inspection and intercostal anesthesia \\ - Suction of pleural fluid; \\ * Look for pleural implants, nodularity, areas of thickened or irregular pleura in visceral or parietal surface; \\ * Intercostal anesthesia with ropivacaine.}

\section{Pleural biopsy}

* Use an electrocautery to cut and delineate the limits of pleural biopsy. Use blunt tools to grab pleural tissue;

* Carefully check hemostasis.

\section{Pleurodesis}

* 3-6 g of talc, using an atomizer connected to an oxygen outlet;

- Spread out talc all over the plural cavity.

\section{Drainage}

* 20-28 F multi-hole chest tube inserted in the caudal incision;

* Suction is normally not used.

\section{Role of team members}

\section{Surgeon}

* Controls the tools in the anterior and posterior incisions.

$1^{\text {st }}$ assistant

* Controls the camera.

$2^{\text {nd }}$ assistant

* Controls retractors in the posterior incision when necessary.

\section{Surgical instrument technician}

* Takes care of material and hands surgical instrument to the surgeon.

\section{Post-operative management}

* Adequate analgesia;
* Early mobilization. Stimulate walking as soon as possible;

* Chest tube removal 24-48 h after surgery if daily volume $<300 \mathrm{~mL} /$ day.

\section{Tips, tricks and pitfalls}

* Caution with pleural adherences before making the first incision. Lung can be attached to the anterior part of chest wall;

* Avoid overuse of opioids in post-op period. Intercostal anesthesia helps to prevent high doses of that medication;

* Carefully select patients for the procedure. The inflammatory response often is very important and can affect renal function and elevate systemic inflammatory markers.

\section{Conclusions}

The treatment of MPE demands special attention to the symptoms of the patient, underlying clinical conditions, primary tumor site and performance status. The availability of medical devices, e.g., IPCs or small-bore catheters as well as day clinic and caregiver support will influence the decision for the best approach.

\section{Acknowledgements}

None.

\section{Footnote}

Conflicts of Interest: The authors have no conflicts of interest to declare.

\section{References}

1. Antony VB, Loddenkemper R, Astoul P, et al. Management of malignant pleural effusions. Eur Respir J 2001;18:402-19.

2. Penz E, Watt KN, Hergott CA, et al. Management of malignant pleural effusion: Challenges and solutions. Cancer Manag Res 2017;9:229-41.

3. Ost DE, Jimenez CA, Lei X, et al. Quality-adjusted survival following treatment of malignant pleural effusions with indwelling pleural catheters. Chest 2014;145:1347-56. 
4. Lorenzo MJ, Modesto M, Pérez J, et al. Quality-of-Life assessment in malignant pleural effusion treated with indwelling pleural catheter: a prospective study. Palliat Med 2014;28:326-34.

5. Roberts ME, Neville E, Berrisford RG, et al. Management of a malignant pleural effusion: British Thoracic Society pleural disease guideline 2010. Thorax 2010;65:ii32-40.

6. Asciak R, Rahman NM. Malignant Pleural Effusion. From Diagnostics to Therapeutics. Clin Chest Med 2018;39:181-93.

7. Feller-Kopman D, Berkowitz D, Boiselle P, et al. LargeVolume Thoracentesis and the Risk of Reexpansion Pulmonary Edema. Ann Thorac Surg 2007;84:1656-61.

8. Tan C, Sedrakyan A, Browne J, et al. The evidence on the effectiveness of management for malignant pleural effusion: a systematic review. Eur J Cardiothorac Surg 2006;29:829-38.

9. Terra RM, Kim SY, Pego-Fernandes PM, et al. Is silver nitrate pleurodesis for patients with malignant pleural effusion feasible and safe when performed in an outpatient setting? Ann Surg Oncol 2011;18:1145-50.

10. Terra RM, Bellato RT, Teixeira LR, et al. Safety and systemic consequences of pleurodesis with three different doses of silver nitrate in patients with malignant pleural effusion. Respiration 2015;89:276-83.

11. Chang S, Hur J, Im DJ, et al. Volume-based quantification using dual-energy computed tomography in the differentiation of thymic epithelial tumours: an initial experience. Eur Radiol 2017;27:1992-2001.

12. Shaw P, Agarwal R. Pleurodesis for malignant pleural effusions. Cochrane Database Syst Rev 2004;(1):CD002916.

13. Andrade Neto JD, Terra RM, Teixeira RM, et al. Safety Profile of the Use of Iodopovidone for Pleurodesis in Patients with Malignant Pleural Effusion. Respiration 2015;90:369-75

14. Terra RM, Junqueira JJM, Teixeira LR, et al. Is full postpleurodesis lung expansion a determinant of a successful outcome after talc pleurodesis? Chest 2009;136:361-8.

15. Robinson LA, Fleming WH, Galbraith TA. Intrapleural doxycycline control of malignant pleural effusions. Ann

doi: 10.21037 /jovs.2018.05.02

Cite this article as: Terra RM, Dela Vega AJ. Treatment of malignant pleural effusion. J Vis Surg 2018;4:110.
Thorac Surg 1993;5 5:1115-21; discussion 1121-2.

16. Araujo PHXN de, Terra RM, Santos T da S, et al. Ultrasound-guided intrapleural positioning of pleural catheters: influence on immediate lung expansion and pleurodesis in patients with recurrent malignant pleural effusion. J Bras Pneumol 2017;43:190-4.

17. de Araujo PHXN, Terra RM, da Silva Santos T, et al. What happens to the pleural space affected by malignant effusion after bedside pleurodesis? J Surg Oncol 2018. [Epub ahead of print].

18. Rahman NM, Pepperell J, Rehal S, et al. Effect of opioids vs NSAIDs and larger vs smaller chest tube size on pain control and pleurodesis efficacy among patients with malignant pleural effusion: The TIME1 Randomized Clinical Trial. JAMA 2015;314:2641-53.

19. Dresler CM, Olak J, Herndon JE, et al. Phase III intergroup study of talc poudrage vs talc slurry sclerosis for malignant pleural effusion. Chest 2005;127:909-15.

20. Terra RM, Teixeira LR, Bibas BJ, et al. Effectiveness and safety of outpatient pleurodesis in patients with recurrent malignant pleural effusion and low performance status. Clinics (Sao Paulo) 2011;66:211-6.

21. Clive AO, Jones HE, Bhatnagar R, et al. Interventions for the management of malignant pleural effusions: a network meta-analysis. Cochrane Database Syst Rev 2016;(5):CD01052.

22. Xia H, Wang XJ, Zhou Q, et al. Efficacy and safety of talc pleurodesis for malignant pleural effusion: A meta-analysis. PLoS One 2014;9:e87060.

23. Thomas R, Fysh ETH, Smith NA, et al. Effect of an indwelling pleural catheter vs talc pleurodesis on hospitalization days in patients with malignant pleural effusion: The AMPLE randomized clinical trial. JAMA 2017;318:1903-12.

24. Davies HE, Mishra EK, Kahan BC, et al. Effect of an indwelling pleural catheter vs chest tube and talc pleurodesis for relieving dyspnea in patients with malignant pleural effusion: The TIME2 randomized controlled trial. JAMA 2012;307:2383-9.

25. Terra RM, Dela Vega AJ. VATS pleural biopsy and talc poudrage pleurodesis. Asvide 2018;5:518. Available online: http://www.asvide.com/article/view/24892 